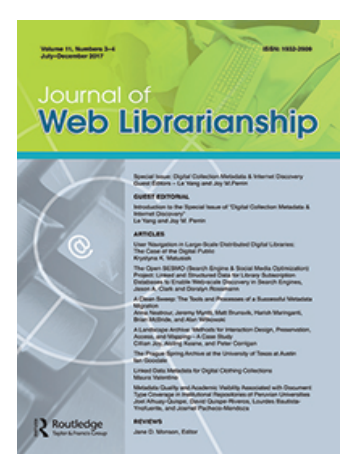

Journal of Web Librarianship

\title{
The Prague Spring Archive at the University of Texas at Austin
}

\section{Ian Goodale}

To cite this article: Ian Goodale (2017) The Prague Spring Archive at the University of Texas at Austin, Journal of Web Librarianship, 11:3-4, 220-230, DOI: 10.1080/19322909.2017.1373041

To link to this article: https://doi.org/10.1080/19322909.2017.1373041

$$
\text { 曲 Published online: } 02 \text { Nov } 2017 .
$$

Submit your article to this journal $₫$

LIII Article views: 70

Q View related articles $₫$

View Crossmark data $\nearrow$ 


\title{
The Prague Spring Archive at the University of Texas at Austin
}

\author{
lan Goodale (iD \\ UT Libraries, The University of Texas at Austin, Austin, Texas, USA
}

\begin{abstract}
There is a noted lack of primary historical documents related to the Prague Spring, one of the key moments in the Cold War, available online. As such, there is a need for an online resource that presents these primary documents in their entirety, allowing researchers and the public to engage with these materials in a user-friendly, open access format. The Prague Spring Archive, a new project at The University of Texas at Austin, fills this gap. This article addresses the development, promotion, and future steps of the project.
\end{abstract}

\section{ARTICLE HISTORY}

Received 24 March 2017

Accepted 25 August 2017

\section{KEYWORDS}

digital archives; digital humanities; digital scholarship; East European studies; global studies; metadata; Slavic studies

\section{Background}

The Prague Spring Archive project is a collaboration between The University of Texas at Austin Libraries and the Center for Russian, East European, and Eurasian Studies at UT Austin, using documents from the Lyndon B. Johnson Presidential Library. The project makes important primary documents on the Prague Spring openly accessible, allowing greater opportunities for public and academic access to the documents through an online portal created in Scalar, an online publishing platform from the Alliance for Networking Visual Culture.

The University of Texas at Austin has the nation's fifth largest academic library, with over 8 million volumes and 17 library locations (The Lyndon B. Johnson Presidential Library n.d.). The University also has over 18 colleges and schools served by these libraries, with more than 3,000 teaching faculty and over 50,000 students from more than 300 degree programs. The Perry-Castañeda Library is the main library within the University of Texas system, and contains major holdings in a variety of subject areas, including humanities and social sciences.

The Center for Russian, East European, and Eurasian Studies (CREEES) was established at The University of Texas at Austin in 1984 and now includes over 60 faculty members from over 20 different departments and administrative units across campus (The University of Texas at Austin n.d.). CREEES is committed to

CONTACT lan Goodale iangoodale@utexas.edu European Studies and Digital Scholarship Librarian, The University of Texas at Austin, 101 E. 21st St., PCL 2.312L, Austin, TX 78712, USA.

Color versions of one or more of the figures in this article can be found online at www.tandfonline.com/wjwl. 
reaching out to the campus community, as well as the broader region, to provide access to speakers from Russia, Eastern Europe, and Eurasia, and activities that will promote interest in the region. As part of the largest university in the state of Texas, the Center has a special responsibility to support continued international development and to educate students who can play a fundamental role in an international community in which Russia, Eastern Europe, and Eurasia are critical players.

Situated on The University of Texas at Austin campus, the Lyndon B. Johnson Presidential Library houses 45 million pages of historical documents, 650,000 photos, and 5,000 hours of recordings from Lyndon B. Johnson's political career, including about 643 hours of his recorded telephone conversations (The Lyndon B. Johnson Presidential Library n.d.). Some collections (both textual and audiovisual) have been digitized for the web, but many more are only available for research in person at the library. The LBJ Presidential Library is part of a system of Presidential libraries administered by the National Archives and Records Administration.

Scalar was chosen for the project due to its reputation as a platform for scholarly publishing in a digital format. The platform's tools allowed for the easy replication of the experience of navigating through a physical archive in the digital format, maintaining the archive's original structural integrity. It also allowed for the seamless integration of additional features exclusive to (Figure 1) the digital portal for the archive. Key documents and figures are curated and highlighted to aid research, an interactive timeline (Figure 2) was created to introduce the basic structure of the Prague Spring crisis to those unfamiliar with its history, and images from the Lyndon B. Johnson Library's photographic archive are paired with other site content to provide a visual reference for figures and events mentioned in the archival documents. Educational activities for high school students are in development to further outreach with the archival materials, including activities that could easily integrate into curricula on the Cold War. For researchers who would like to explore what is available in the physical collections of the LBJ Presidential Library, the finding aid for the entire archival collection is also available on the site.

The Prague Spring was a period of political liberalization in communist Czechoslovakia that marked a significant point of resistance against the Soviet regime, and which was eventually suppressed by an invasion of Warsaw Pact forces. It is important to researchers examining the Cold War as an example of an Eastern Bloc country undergoing a process of peaceful revolution from within, as well as case study in militaristic suppression of such revolution by the Soviet Union. The crisis would foreshadow the eventual fall of the Soviet Union, and the documents in the project have still broader appeal as examples of how the United States government developed political strategy in response to both the initial liberalization and the Soviet Union's harsh repression. The declassified primary documents we have digitized reveal U.S. attitudes toward communist 
governments, its attempts to further U.S. interests in East Europe, and its approaches to public relations and diplomacy in the face of a perceived Communist threat.

Work on the project first began in 2015. With funding from a U.S. Department of Education Title VI National Resource Centers grant and the Texas Chair in Czech Studies, digitization work on an initial selection of archival boxes was completed by undergraduate students from the CREEES and MSIS graduate students working at the University of Texas Libraries. Digitization work is ongoing, with new materials being photographed, processed, and added to Texas ScholarWorks, the institutional repository at The University of Texas Austin, by MSIS graduate student Nicole Marino and the author, the European Studies and Digital Scholarship Librarian.

To help maintain the archival integrity of the materials in their digitized format, extensive metadata was created to accompany the documents within the Texas ScholarWorks repository. The metadata allows researchers working with the materials within Texas ScholarWorks to easily search the documents, and can be downloaded by anyone through the repository. The metadata was prepared using Excel spreadsheets to assist with batch uploads to the repository, with rows corresponding to individual documents and rows corresponding to various Dublin Core metadata elements that would become searchable once online. These Dublin Core elements included the Title, Date Created, a number of Subject fields with Library of Congress standardized subject headings, a Description, the Type of the document (e.g., "Correspondence"), its Creator, and the Language of the document. The project team also included non-Dublin Core filename identifiers, which were used by staff in the Digitization department and the institutional repository to link the uploaded files to their respective metadata. Full-text of the documents will soon be added in XML format to accompany the archival PDFs, increasing searchability and providing an additional resource for working with the documentsmaking digital humanities practices such as text mining or sentiment analysis easier to accomplish, for example. The XML files are generated through the optical character recognition (OCR) program DocWorks, and are monitored for accuracy and edited as needed by MSIS graduate students working with the University of Texas Libraries.

\section{Promoting the archive}

A variety of strategies were used to facilitate discovery of the archive online. The author sent e-mails to listservs read widely by scholars and librarians in subject areas relevant to the project, which succeeded in raising its profile. After publicizing the project in this way, the author was contacted by researchers who invited him to publish an additional write-up in two academic newsletters, Czech Language News and ASEEES NewsNet, which further broadened the audience for the project. Links to the project were also added 


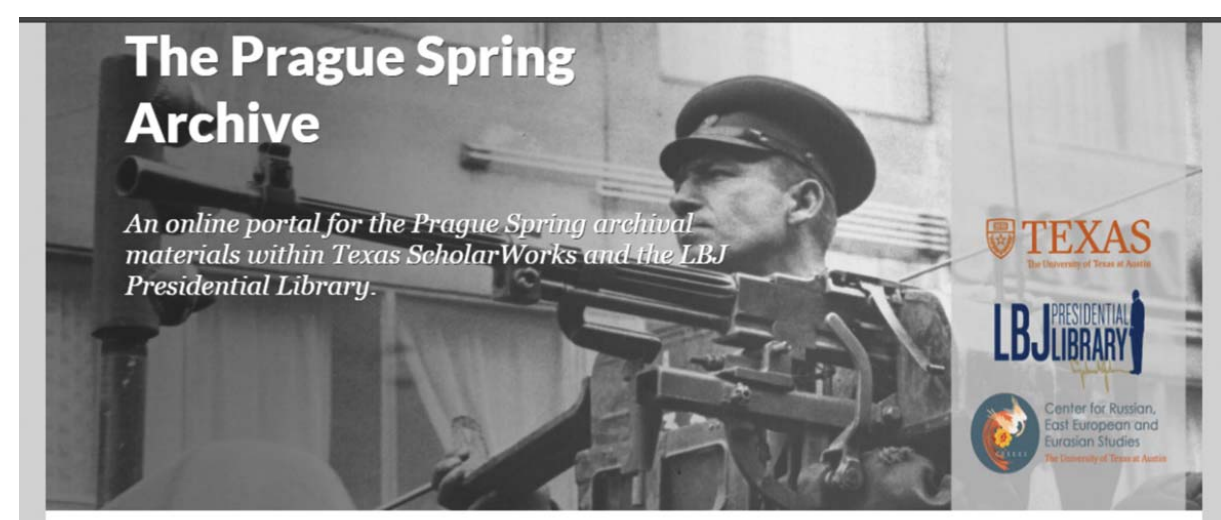

The University of Texas at Austin Libraries have partnered with the Lyndon Baines Johnson

Presidential Library and the University of Texas at Austin's Center for Russian, East European, and Eurasian Studies to digitize archival materials from the LBJ Presidential Archive's collections. The full collection can be browsed at Texas ScholarWorks, and individual boxes can be browsed here.

Below you will find links to our guides to Box 179 and Box 180 of the archival holdings, a page on key figures in the Prague Spring, a timeline of events in the Prague Spring, a collection of key documents from Box 179 and Box 180, a guide to using Texas ScholarWorks to search and download additional documents, and a finding aid for the physical collections housed in the LBJ Presidential Library. More content on additional archival boxes will be added in the future. The site can also be navigated using the drop-down menu in the top left of your screen ( $\vdots$ ).

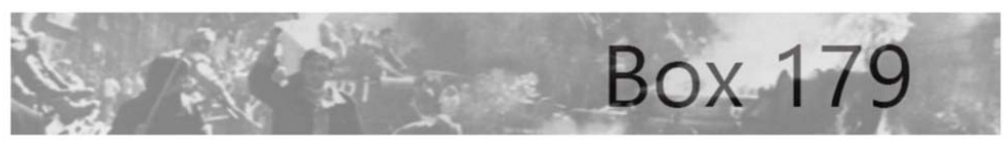

Figure 1. The homepage of the Prague Spring Archive.

to LibGuides administered by librarians at a number of institutions in the United States and Canada, expanding the reach of the project. This has enabled the project to be advertised in ways the author has not directly deployed, which has further allowed the project to be broadcast to a wider audience. It has also allowed the project team to build relationships with scholars working in relevant fields, as well as librarian colleagues.

The author contributed write-ups to raise the project's profile on his home campus as well. Mary Neuburger, the Director of the CREEES, spoke with Joan Neuburger, the director of the Not Even Past (NEP) website, about publicizing the project there. To that end, Mary and the author collaborated on an article describing the project's timeline, scope, and goals for the future that was featured on the NEP site. In addition, the author wrote a description of an important document from the archival collection that was likewise published on the NEP website. This write-up gave historical context for the document, providing background on the importance of the collection as a whole, while simultaneously foregrounding the project and further increasing interest in its materials.

The author also contributed a write-up for the University of Texas Libraries' website. This helped raise the profile of the project on campus, and provided the communications staff at the Perry-Castañeda Library with information that could 
The following timeline highlights key events preceding, during, and following the Prague Spring. Please click the arrow buttons to navigate the timeline chronologically, or click specific dates to explore the timeline in a different order.

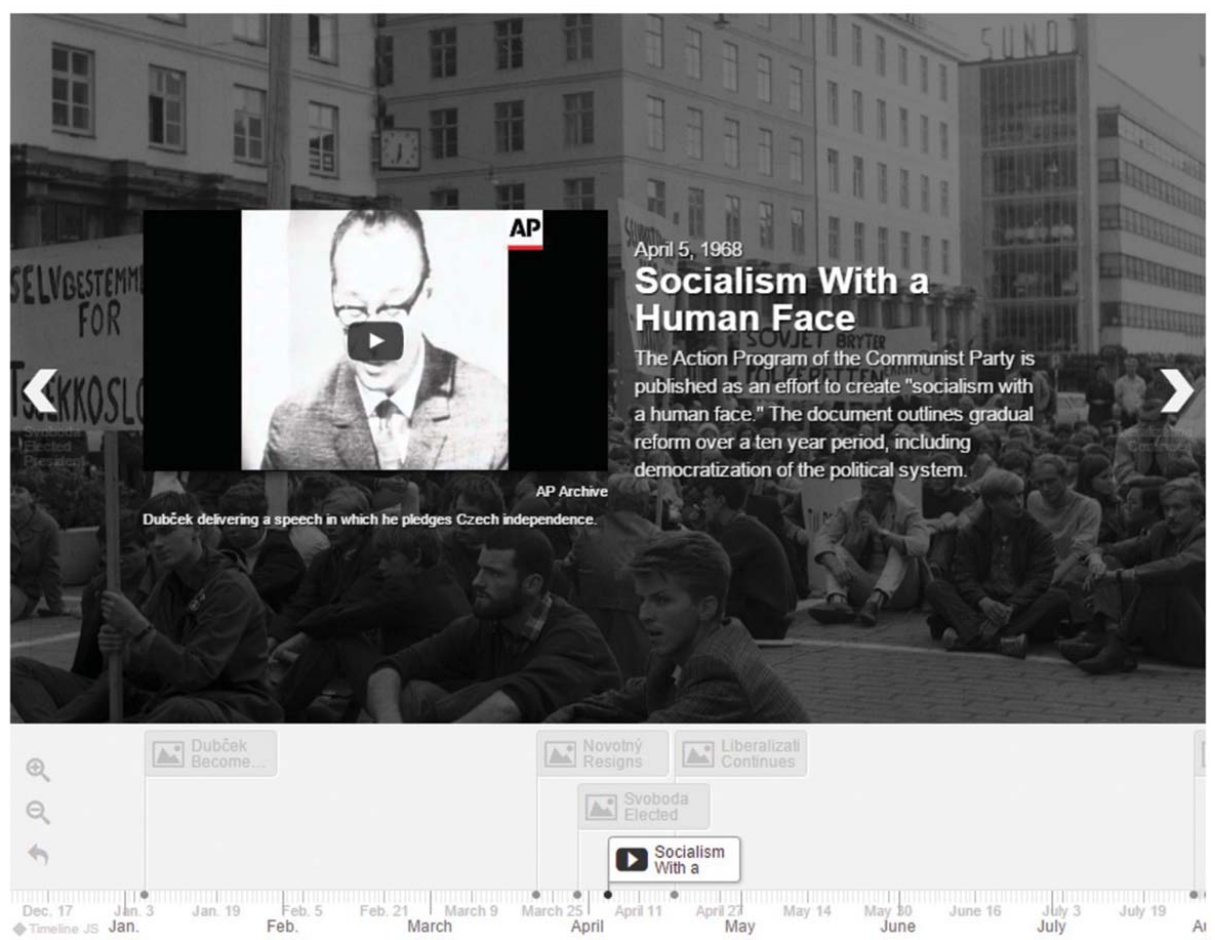

Figure 2. An interactive timeline of the events preceding, during, and following the Prague Spring. This particular slide includes an embedded video of Dubček pledging Czechoslovak independence.

be used to advertise the project elsewhere. Through this connection with the communications staff, the project was later featured on the Library Journal's InfoDocket, which in turn led to further coverage on MIT's $h+d$ insights page. In addition, the author added links to the portal to his LibGuides, integrating the resource into his own outreach to students.

The author was active in promoting the project on social media. The author promoted the project using his professional Twitter account, providing links to the project and tagging appropriate parties in his tweets. By mentioning Scalar, the author was able to garner attention from the official account of the platform, which retweeted the link to the project and further broadened the reach of the project. The author also worked with a faculty member to post about the project on a Facebook group for Slavic Digital Humanities, which further broadened the reach of the project.

This outreach on Twitter led to contact and discussions of future collaboration with Socialism Realised, an online project aimed at providing an understanding of people's daily lives under communist governments, whose administrators reached out to the author after seeing one of his tweets. The publicity generated online also enabled the author to more easily make the case for 


\section{Box 180, Folder 4}

\section{Folder 4 (145 pages) - 1968}

Contents:

Contains many documents detailing $\square$ world and European reactions to the Warsaw Pact Forces' invasion of Czechoslovakia, with mention of protests in Belgium and condemnations of the invasion by the Danish Labor Federation, Finnish politicians, French Communists, and Austrians. Press, public, and governmental reactions are all noted. The USSR's explanation of the invasion to other countries is also detailed, as well as communications between Czech politicians and American ambassadors abroad.

Key Documents:

- Memo and Report Regarding Reactions to Czech Situation

- Intelligence Information Cable on French Reaction to Czech Situation

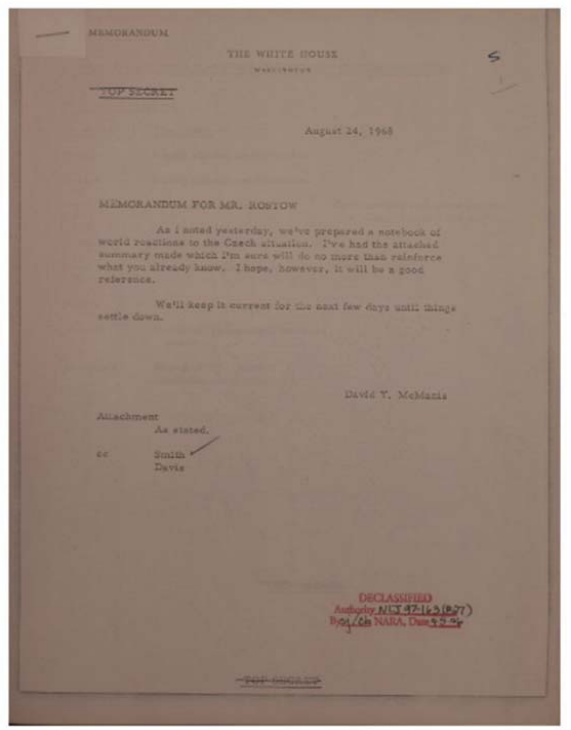

Figure 3. A page highlighting key documents from Box 180, Folder 4 in the Prague Spring Archive, with text contributed by graduate students.

collaboration with Baylor University's Keston Center, whose staff agreed to digitize relevant archival materials for the project team as a way to supplement the Prague Spring Archive's online collection of documents. The team plans to link to these newly digitized materials, which will be hosted by Baylor, from the Prague Spring Archive's online portal, which will benefit both institutions in increasing access to their collections and broadening their impact with researchers looking for primary source materials online.

The project's online presence and mention in other outlets also led to the project team being contacted by staff from the National Czech and Slovak Museum, who are planning to use a document from the collection in an upcoming curriculum for public school students in Iowa. This will lead not only to direct use of the materials by students studying East European history, but also to a general broadening of the project's audience by expanding its profile outside of academia. Furthermore, the team hopes to develop its own educational materials for use by public school educators in the future, which will be made available freely on the project's online portal and similarly increase its reach. Mary Neuburger will use the project again in a future iteration of her graduate seminar, as well, which will introduce the materials to yet another new class of graduate students and researchers on campus. 


\section{Building the archive}

Librarians have been increasingly involved in digital humanities projects that serve both a pedagogical purpose and a research purpose (Varner 2016). This project was a conscious attempt to increase the active participation of the libraries at The University of Texas at Austin with such projects on campus, and to build relationships with departments and nearby cultural heritage institutions in the process. This type of relationship building has been identified as a key value for cultural heritage institutions working on digital projects in the past (Rizzo 2016), and is something that the project team wanted to cultivate as a way to strengthen its ties to other institutions, simultaneously enhancing the Prague Spring Archive and helping other institutions. As a result of this effort, the Prague Spring site has been an important aspect of embedded librarianship at The University of Texas Libraries. The author worked with graduate students in a graduate seminar taught by Mary Neuburger, REE 381: Russian, East European, and Eurasian Civilizations and Cultures, to have the students contribute text for incorporation into the online portal, visiting multiple class sessions to teach about the project and serve as a contact for digital scholarship and metadata-related questions the students might have. The students also selected key documents from archival folders to be highlighted on the portal (Figure 3), and provided input on the site's design and features throughout its development. Professors Mary Neuburger and Vlad Beronja contributed their input on design and content, helping to write descriptions of archival materials and select key documents to profile. The finished portal was then presented to the class for additional feedback, and more content from future iterations of the class will be added shortly.

This collaborative approach has been used in digital archives projects in the past (Norcia 2008). Students use the materials as an integral part of the graduate seminar, going through metadata created by librarians and graduate student research assistants at the library and selecting their documents. This assignment was created to serve multiple purposes, as it increases their familiarity with the Prague Spring events, contributes to the development of content for the online archive, and enables them to gain familiarity with metadata standards and experience working on a digital project. This increased their information literacy while giving them experience working with primary archival sources, and allowed them to gain experience navigating the materials in The University of Texas's institutional repository, as well. This likewise served to strengthen the Libraries' relationship with the community of scholars and students on campus while simultaneously introducing new graduate students to possible areas of interest for their research.

Students will use the archive's materials for assignments in future classes, working with professors and librarians to contribute content to the site and identify documents of interest to their personal research in the archive. The project team 
hopes that through publicizing and promoting the archive, the materials it contains will be of use not only to students, but to researchers with interest in these documents who will be able to easily access the materials without traveling to the physical archives in Austin.

The author also carried out the entirety of the web design component of the project as a way to expedite and simplify the process of the portal's creation. The author was able to incorporate his skills in Photoshop, HTML and CSS, and web design to create an attractive, easy-to-use portal that could be effectively tested with users for further refinement. Early prototypes of the site were shown to students in a graduate seminar for feedback, which was incorporated into its final iteration. Faculty input from Mary and Vlad was also helpful and incorporated into the website's final design.

An important debate in the field of digital humanities is the way its utilization of technologies noted for their ease of access and participation relates to the idea of democratizing the humanities (Hunter 2015). Scalar was chosen in part due to its ease of access and possibilities for open collaboration between graduate students and librarians, so the possibilities for democratization and equal participation in digital humanities work was an important consideration for the project team during the project's conception. The development plan for the project was intentionally constructed as a collaborative process, with a division of labor that best suited the strengths of all the project's collaborators. MSIS graduate students worked on creating metadata that conformed to an agreed upon set of standards, which ensured that metadata created for the project's items remained as uniform as possible. Maintaining a solid, standardized language and format for the project's metadata was a key aspect of the team's approach to creating effective metadata for the project, as by keeping it uniform we were able to ensure that the project remained uniformly accessible. Digitization work was carried out by a small number of graduate students who were trained by staff in the Digital Stewardship Department of the Libraries. Effective project management ensured the quality of the content being captured and processed while simultaneously streamlining and equitably dividing labor. Graduate students in the Department of Russian and East European Studies helped identify key documents and provide text that was later adapted for inclusion on the website.

Collaboration with the institutional repository on the project has also been a key aspect of institutional support for the project. The author has worked closely with both the Digitization Department of the Libraries and the managers of the repository to ensure the successful completion of the backend of the project, and they have helped spread the word about the work to others, which has further broadened the project's audience. The repository provides a stable, institution-specific solution to document hosting that the Prague Spring Archive portal can easily interface with, and is a key aspect of institutional support for the online archive. 


\section{Interface design}

The author wrote custom HTML to alter the appearance of elements in the project's pages, allowing him to take advantage of Scalar's extensive options for customization. The author altered the positioning of navigational elements on the page, creating a custom interface separate from Scalar's built-in navigational options. The author's custom series of clickable images, with text overlaid on historical photographs available either in the public domain or under a Creative Commons license, both increased the visual appeal of the homepage and provided users with a readily comprehensible, visual interface with which to navigate the site. This increased usability, allowing users to utilize built-in navigation menus (accessible by clicking a thumbnail in the corner of the screen) or the site's custom buttons, available directly on the homepage, to navigate the site according their preference.

The author used Photoshop to create customized header images for each page, utilizing images in the public domain or available under a Creative Commons license as material that could be edited as necessary. To improve the appearance of the banners within Scalar's interface, images were cropped, brightness and contrast were altered, text was added, and sections of the images were separated into their own layer within Photoshop. This separation allowed for the altering of these sections to improve the appearance of the text placed over them, namely by lightening and altering the contrast on these sections to make the text appear more clearly. The clickable images used as navigation buttons on the homepage were created in Photoshop using a similar process.

\section{Enhancing searchability}

Adding full-text of the documents in XML format will increase accessibility of the documents by making their full text searchable in The University of Texas's institutional repository. The work of generating these XML files is still underway, and is being obtained by running digitized copies of the documents through the OCR program DocWorks. A graduate student is manually correcting the OCR text generated by the program, then exporting the clean XML files to a local server, where they will live until they can be uploaded to the online repository. Once in the repository, they will be linked to the archival PDFs of their respective documents and directly accessible through their respective documents' pages.

The author felt it was important to use a free, open source tool like Scalar for the project, as supporting such tools by using them for large, institutionally-supported projects both strengthens their profiles and serves his institution's commitment to supporting open information in digital scholarship. The project team seeks, by utilizing such technologies, to open the physical archive and make its information freely, easily accessible to all, regardless of whether they are able to visit the physical repository where the actual archival documents reside. As such, the team hopes to join a community of librarians, scholars, and researchers who seize the opportunities digital humanities and open access 
provide for making knowledge freely available to as broad an audience as possible (Suber 2012).

\section{Future directions}

The project was somewhat experimental, but inspired the project team to continue both its own development and to explore future directions for digital initiatives within the University of Texas Libraries. One of the key aspects of the project's success was the implementation of collaborative workflows combined with having one person hone in on specific elements of the project (e.g., the author took control of web design and metadata creation, while MSIS candidate Nicole Marino performed digitization work). It was vital to keep work on the project collaborative, while allowing individuals to explore their individual strengths and successfully apply themselves to areas on which they could singularly focus. This approach will continue to be implemented in this project as it develops, and will be applied in other projects at the Libraries as well.

One unsuccessful strategy implemented early on in the project's lifespan was the division of metadata creation among different graduate students. Despite the standardized format of the metadata, individual differences in writing styles for the item descriptions and titles resulted in metadata that required some correction to make fully uniform. For this reason, the author plans to either create the metadata on his own or to have one student under his direct supervision create the metadata to the project's specifications in the future.

This project stands out due to its collaborative nature across institutions; its integration of instruction and work between professors, librarians, and graduate students; and its appeal to scholars working in a variety of areas. The work undertaken by the graduate students not only contributed content to the site, but was designed to increase their familiarity and literacy with metadata formats and working directly with primary documents. The subject of information literacy was considered especially important due to the seminar being comprised entirely of first-year graduate students, whose work directly impacted the content of the online portal.

This project also stands out in that while it was conceived of and worked on primarily by Slavists, its scope is broad enough to be of interest to researchers working in a variety of other areas, such as history or political science. While many digital projects have been carried out in the humanities, the team sees the Prague Spring Archive as both a humanities project and one that while multidisciplinary, also fits into the growing number of Slavic digital humanities projects being undertaken by research libraries (Trehub 2009). While these projects represent a significant step forward in the development of digital projects in the Slavic field, only one other project specifically addresses primary documents from the Cold War (Lawrence 2013), and none focus on the Prague Spring. While projects such as the Wilson Center archive reference documents from U.S. sources related to the Cold War, none make a specific corpus of such primary sources available online as 
this project does (Remnek 2007). Thus, the Prague Spring Archive project represents an addition to an existing lineage of diverse Slavic digital humanities projects (Digital Humanities in the Slavic Field 2017), as well as a unique contribution to the field.

\section{About the author}

Ian Goodale is the European Studies and Digital Scholarship Librarian at the University of Texas at Austin. He is a member of the Collection Development Subcommittee within the Association for Slavic, East European and Eurasian Studies' (ASEEES) Committee on Libraries and Information Resources. He is interested in the intersections of librarianship, digital humanities, archives, and UX/UI design.

\section{ORCID}

Ian Goodale (iD) http://orcid.org/0000-0002-6685-2949

\section{References}

Austin, The University of Texas at. n.d. Facts and figures. Accessed March 10, 2017. https:// www.utexas.edu/about/facts-and-figures.

Digital Humanities in the Slavic Field. 2017. Digital humanities in the Slavic field. Accessed July 2017. http://www.slavic-dh.org/directory/.

Hunter, A. 2015. The digital humanities and democracy. Canadian Journal of Communication 409.

Lawrence, M. A. 2013. Cold war international history project digital archive. Journal of American History 100: 947-948. doi:10.1093/jahist/jat522.

Norcia, M. A. 2008. Out of the ivory tower endlessly rocking: Collaborating across disciplines and professions to promote student learning in the digital archive. Pedagogy 8: 91-114.

Remnek, M. B. 2007. Access to East European and Eurasian culture: publishing, acquisitions, digitization, metadata. Binghamton, NY: Haworth Information Press.

Rizzo, M. 2016. History at work, history as work: Public history's new frontier. American Quarterly 68: 205-218. doi:10.1353/aq.2016.0000.

Suber, P. 2012. Open Access. Cambridge, MA: MIT Press.

The Lyndon B. Johnson Presidential Library. n.d. About. Accessed March 07, 2017. https:// www.lbjlibrary.org/page/library-museum/.

The University of Texas at Austin. n.d. The Center for Russian, East European, and Eurasian Studies. Accessed March 8, 2017. https://www.liberalarts.utexas.edu/slavic/CREEES/AboutCREEES.php.

The University of Texas Libraries. n.d. About the Libraries. Accessed March 10, 2017. https:// www.lib.utexas.edu/about.

Trehub, A. 2009. Slavic studies and Slavic librarianship' revisited: Notes of a former Slavic librarian. Slavic \& East European Information Resources 172.

Varner, S. 2016. Library instruction for digital humanities pedagogy in undergraduate classes. In Laying the Foundation: Digital Humanities in Academic Libraries, ed. John W. White and Heather Gilbert, 206. West Lafayette, IN: Purdue University Press. 